\title{
PERFORMANCE MODEL FOR ASPHALT CONCRETE PAVEMENT BASED ON THE FUZZY LOGIC APPROACH
}

\author{
Mustafa Karaşahin ${ }^{1}$, Serdal Terzi ${ }^{2}$ \\ ${ }^{1}$ Faculty of Engineering, Istanbul University, Istanbul, Turkey \\ ${ }^{2}$ Faculty of Technical Education, Süleyman Demirel University, Isparta, Turkey
}

Submitted 1 July 2011; accepted 30 May 2012

\begin{abstract}
Accurate pavement performance estimation is very important for the managing and maintaining of surface transportation infrastructure. In the present study, a new model for the prediction of present and future performance of flexible pavements is developed using the fuzzy logic approach. The database of the model is able to use numerical measurements and also linguistic statements. Many models developed in the literature neglect the parameters that have little bearing on performance. However, it is a well known fact that these parameters do have an effect on performance to some degree. Different parameters were considered in the model as accepted by the authorities, and as having little bearing on performance. For each parameter, a certain weight was appointed, and the parameters that affected performance were assigned greater weights while the others were assigned smaller weights. As a result, the current model in the fuzzy logic approach is more flexible than the current Pavement Serviceability Index (PSI) and Pavement Condition Index (PCI) models. The model is different from previous fuzzy logic based models. Two stages of the fuzzy logic approach were used in these models. Since this new methodology does not need any mechanical tests, the model can be adopted by the Pavement Management System (PMS) of developing countries.
\end{abstract}

Keywords: pavement performance, performance prediction, fuzzy logic.

Reference to this paper should be made as follows: Karaşahin, M.; Terzi, S. 2014. Performance model for asphalt concrete pavement based on the fuzzy logic approach, Transport 29(1): 18-27.

http://dx.doi.org/10.3846/16484142.2014.893926

\section{Introduction}

Pavement performance is a function of its relative ability to serve traffic over a period of time. Relative ability of pavement in service was determined quite subjectively by visual inspection and experience. However, individual decisions made from similar data were often inconsistent. After the 1950s, measurements such as roughness, deflection and skid resistance began to appear that could quantify pavement performance. After the AASHO Road Test was established (AASHO 1962) the Present Serviceability Rating (PSR) based on individual observation was developed. The PSR ranges from 5 (excellent) to 0 (impassable). Since PSR is based on passenger interpretations of ride quality, it gives us an idea about pavement roughness. The Present Serviceability Index (PSI) is based on the original PSR. Since PSR was a ride quality rating that required a panel of observers and was not practical for large scale networks, a nonpanel based system was needed. Therefore PSR values of various roads in Illinois, Minnesota and Indiana were obtained by a panel of raters and this information was then correlated with various pavement measurements, such as profile and cracking, to develop Pavement Serviceability Index (PSI) equations. PSI is based on the same five-point rating system as PSR.

Setting the priorities for pavement maintenance and rehabilitation depends on the availability of a universal scale for assessing the condition of every element in the network. The condition of a pavement section has traditionally been assessed by several condition indexes. The Present Serviceability Index (PSI) is one common evaluator used to describe the functional condition with respect to ride quality. The Pavement Condition Index (PCI) is another commonly used index to describe the extent of distress on a pavement section (Shoukry et al. 1997). PCI is based on the visual inspection of pavement distresses. Although the relationship between pavement distresses and performance is not well defined, there is general agreement that the ability of a pavement to

Corresponding author: Serdal Terzi

E-mails: serdalterzi@sdu.edu.tr,serdalterzi@gmail.com 
sustain traffic loads in a safe and smooth manner is adversely affected by the occurrence of distress. The rating method provides a procedure for uniformly identifying and describing pavement distress in terms of severity and extent. The mathematical expression for PCI provides an index reflecting the composite effects of various distress types, their severity and their extent on the overall condition of the pavement (Saraf 1998; Shahin 2006).

Prediction of future pavement condition is not only essential for maintenance budget forecasting at the network level but also for determining the most cost-effective rehabilitation strategy at the project level (Bandara, Gunaratne 2001). The knowledge of future pavement performance is also essential to sound pavement design and life-cycle economic evaluation at the project level of pavement management. At the network level, such information is important to ensure adequate financial funding and budgeting (Fwa, Sinha 1986).

Pavement failure is a variable event that not only depends on layer material properties, environmental and subgrade conditions and traffic loading, but also on the specific definition of failure adopted by the highway agency. Failure can be defined in terms of amount of cracking, rut depth, surface roughness, or combinations of these or other indicators of performance (Madanat et al. 2002).

Many pavement deterioration models are based on regression techniques (AASHO 1962; Akhter, Witczak 1985), neural networks (Attoh-Okine 1999, 2001; Choi et al. 2004; Terzi 2007; Kargah-Ostadi et al. 2010), and Markovian processes (Haas et al. 1994; Butt et al. 1995). The basic shortcoming of current models is the lack of uniqueness due to their dependency on data used to generate their formulas. These types of models need more historical data to predict accurate pavement performance. It can be said that a disadvantage of the models is that they can only be used in the section where data are collected since the model calibration is only valid for the considered section.

Subjective evaluations can be analysed using fuzzy set mathematics. Therefore, in response to the need for analytical tools that can incorporate subjective judgment and qualitative evaluations in pavement management systems, several researchers in recent years have explored the use of fuzzy sets (Juang, Amirkhanian 1992; Shoukry et al. 1997; Cheng et al. 1996; Bandara, Gunaratne 2001; Bianchini, Bandini 2010; Pan et al. 2011; Moazami et al. 2011).

In the present study, a fuzzy logic approach was developed to predict pavement performance without using any mechanistic measurements, such as deflection or profile data. The model contains all possible distresses in asphalt pavements and allows predictions of the present and future performance of the pavement. The model is especially suitable for the PMS of developing countries and low volume roads. Many developing countries have a limited number of road rater equipment to collect data for all networks. Therefore, highway agencies generally use the equipment to collect data for high volume roads rather than low volume roads.

\section{Pavement Performance}

Performance is a general term for pavements in changing conditions or serving an intended function with accumulative use (Lytton 1987). For performance analysis, some information is needed on the history of the riding quality of a particular section of pavement for a chosen time period, and the traffic during that time. This can be determined by periodic observations or measurements of the pavement riding quality coupled with records of traffic history and time. It is the history of deterioration of the ride quality or serviceability provided for the user, which defines pavement performance, as shown in Fig. 1 (Haas et al. 1994).

The Present Serviceability Index (PSI) is based on the original AASHO Road Test. Basically, the PSI was a ride quality rating that required a panel of observers to actually ride in an automobile over the pavement in question. Since this type of rating is not practical for large-scale pavement networks, a transition to a nonpanel based system was needed. Table 1 shows PSI rating scale.

Table 1. PSI rating scale

\begin{tabular}{cll}
\hline PSI & Ride rating & \multicolumn{1}{c}{ Appearance rating } \\
\hline 100 & $\begin{array}{l}\text { New - no } \\
\text { roughness } \\
\text { or cracks }\end{array}$ & Looks dark and smooth \\
\hline 80 & $\begin{array}{l}\text { Minor } \\
\text { roughness }\end{array}$ & $\begin{array}{l}\text { Cracks cannot be felt while driving; } \\
\text { Minor cracks are barely visible }\end{array}$ \\
\hline 60 & $\begin{array}{l}\text { Noticeably } \\
\text { rough }\end{array}$ & $\begin{array}{l}\text { Cracks can be felt while driving; } \\
\text { Cracks are clearly visible; } \\
\text { Weathered surface }\end{array}$ \\
\hline 40 & Very rough & $\begin{array}{l}\text { Transverse cracks at short intervals; } \\
\text { Longitudinal cracks present }\end{array}$ \\
\hline 20 & Very rough & $\begin{array}{l}\text { Difficult to maintain speed; } \\
\text { Heavily distressed; } \\
\text { Transverse, longitudinal and block } \\
\text { cracking present }\end{array}$ \\
\hline
\end{tabular}

To transition from a PSR serviceability measure (panel developed) to a PSI serviceability measure (no panel required), a panel of raters during 1958 to 1960 rated various roads for PSR. This information was then correlated to various pavement measurements (such as slope variance (profile), cracking, etc.) to develop PSR equations. Thus, although PSI is based on the same 5 -point rating system as PSR it goes beyond a simple assessment of ride quality (AASHO 1962; Nakamura 1962):

$P S R=5.03-1.91 \cdot \log (1+S V)-0.01 \cdot \sqrt{C+P}-1.38 \cdot R D$,

where: PSI - the Present Serviceability Index; $S V$ - the mean of the Slope Variance in the two wheel paths; $C+P-$ a measure of cracking and patching in the pavement surface; $R D$ - a measure of rutting in the wheel paths.

The PCI is a numerical index, ranging from 0 for a failed pavement to 100 for a pavement in perfect condi- 
tion. Calculation of the PCI is based on the results of a visual condition survey in which distress type, severity, and quantity are identified. The PCI was developed to provide an index of the pavement's structural integrity and surface operational condition. The distress information obtained as part of the PCI condition survey provides insight into the causes of distress and whether it is related to load or climate.

The degree of pavement deterioration is a function of distress type, distress severity, and amount or density of distress. Producing one index that would take into account all three factors was a considerable challenge. To overcome this challenge, 'deduct values' were introduced as a type of weighing factor to indicate the degree of effect that each combination of distress type, severity level, and distress density has on pavement condition. The deduct values were developed based on in-depth knowledge of pavement behaviour, input from many experienced pavement engineers, field testing and evaluation of the procedure, and accurate descriptions of distress types and severity levels. The sum of the deduct values is corrected based on the number and value of the deducts and the corrected sum is subtracted from 100 to obtain the PCI (Shahin 2006; Saraf 1998) The mathematical expression for PCI is as follows:

$$
P C I=100-\sum_{i=1}^{n} \text { Deduct }_{i},
$$

where: $n$ - number of observable distresses; Deduct weight for distress, weight for severity, weight extent.

Traffic data is used in pavement management for the prediction of performance and the assignment of priorities during the selection of rehabilitation projects. For the selection of projects, a measure of traffic volumes is suitable. The Average Annual Daily Traffic (AADT) is a common measure of total traffic on the section (Jung et al. 1976; Haas et al. 1994; Tavakoli et al. 1992). It is the total volume of vehicle traffic of a highway or road for a year divided by 365 days. Performance modelling, on the other hand, requires an estimate of heavy vehicle traffic, which generates the majority of distress. The usual measure is total $8.2 \mathrm{t}$ (18-kip) Equivalent Single-Axle Loads (ESAL) which can be used to estimate the quantity of vehicles that damage the pavements or that the pavement has carried or is expected to carry (Fwa, Sinha 1991, 1992; Berger et al. 1991; Owusu-Ababio 1998; Prozzi, Madanat 2003). However, in some of the studies, only pavement age or traffic was considered (Figs 1 and 2), (Shahin, Becker 1984). In the development of this model, ESAL was considered. ESAL was calculated as flexible pavement ESAL equation (AASHTO 1993) that was given in below:

$$
\begin{aligned}
& \frac{W_{x}}{W_{18}}=\left(\frac{L_{18}+L_{2 s}}{L_{x}+L_{2 x}}\right)^{4.79} \cdot\left(\frac{10^{\frac{G}{\beta_{x}}}}{10^{\frac{G}{\beta_{x 18}}}}\right) \cdot\left(L_{2 x}\right)^{4.33} ; \\
& G=\log \left(\frac{4.2-p t}{4.2-1.5}\right) ;
\end{aligned}
$$

$$
\beta=0.4+\frac{0.081 \cdot\left(L_{x}+L_{2 x}\right)^{3.23}}{(S N+1)^{5.19} \cdot L_{2 x}^{3.23}},
$$

where: $W$ - axle applications inverse of equivalency factors (where $W_{18}=$ number of $18000 \mathrm{lb}(80 \mathrm{kN})$ single axle loads); $L_{x}$ - axle load being evaluated (kips); $L_{18}-$ 18 (standard axle load in kips); $L_{2}$ - code for axle configuration ( 1 - single axle, 2 - tandem axle, 3 - triple axle); $x$ - axle load equivalency factor being evaluated; $s$ - code for standard axle ( 1 - single axle); $G$ - a function of the ratio of loss in serviceability at time $t$, to the potential loss taken at a point where $p_{t}=1.5 ; p_{t}$ - 'terminal' serviceability index (point at which the pavement is considered to be at the end of its useful life); $\beta$ - function which determines the relationship between serviceability and axle load applications; $S N$ - structural number.

Material and construction quality can also affect performance; therefore, any pavement performance model should contain these factors, which may be obtained from pavement construction records. These parameters are especially important in predicting the future performance of newly constructed or rehabilitated pavements. If high quality materials were used in the pavement construction, one could expect to see a longlasting pavement that is performing well. Therefore, if pavement history is available, the pavement performance model should contain these parameters.

Environmental factors are also considered regarding pavement performance and pavement structure de-

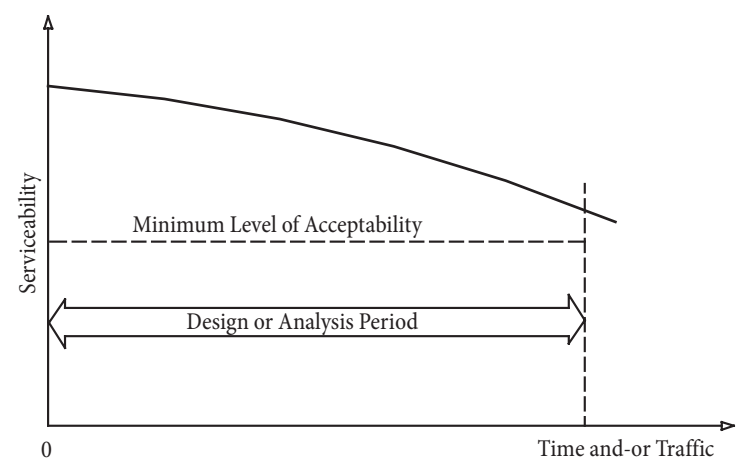

Fig. 1. Deterioration of ride quality or serviceability (Haas et al. 1994)

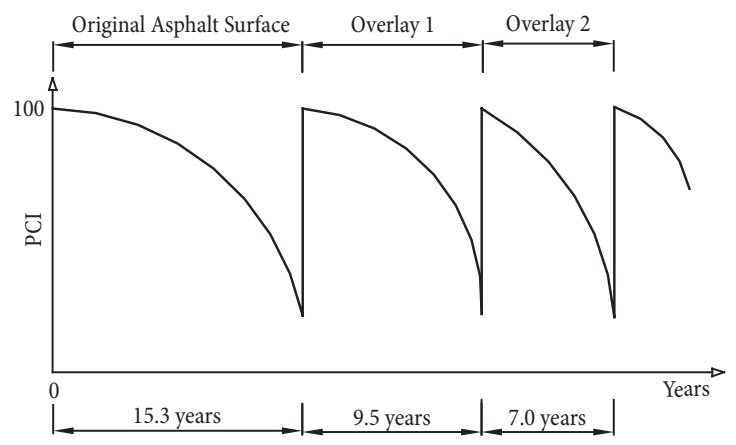

Fig. 2. Average age of asphalt surface before overlay (Shahin, Becker 1984) 
sign. For instance, temperature affects the creep properties of asphalt concrete, thermal-induced stresses in asphalt concrete, and the freezing and thawing of roadbed soil. Since temperature is one of the main reasons for many distresses, care was taken to include it in the model.

Drainage of water from pavements has always been an important consideration in road design; however, current methods of design have often resulted in base courses that do not drain well. This excess water combined with increased traffic volumes and loads often leads to early pavement distress in the pavement structure (AASHTO 1986). As the water content of bases and subbases increases, there is a reduction in supporting power and an increase in the rate of loss of serviceability of the pavements. Free water in hot-mix asphalt (HMA) pavements contributes to shrinkage cracking and to oxidation and loss of flexibility, which can lead to cracking and general deterioration of wearing courses and stabilized bases. Free water is almost always associated with the breaking out of chunks of pavements constructed of two or more successive layers of similar paving material (Cedergren 1974). Therefore, since the drainage is generally neglected in developing countries, many asphaltic-concrete pavements lose service capability at a relatively early stage. For this reason drainage needs to be included in any pavement performance model.

In the past, pavement condition was often determined quite subjectively by visual inspection and experience. Therefore, individual decisions made from similar data were often inconsistent. Determination of pavement performance consists of some degree of fuzziness and the fuzzy logic modelling technique is one of the best approaches with which to handle fuzziness.

\section{Fuzzy Logic Approach}

The basic elements of each fuzzy logic system are, as shown in Fig. 3, rules, fuzzifier, inference engine, and defuzzifier. Input data are most often crisp values. The task of the fuzzifier is to map crisp numbers into fuzzy sets (cases are also encountered where inputs are fuzzy variables described by fuzzy membership functions). Models based on fuzzy logic consist of 'If-Then' rules.

For fuzzy rule-based systems, the rule base is formed with the assistance of human experts. Recently, in some research, numerical data has been used as well as a combination of numerical data-human experts. An interesting case appears when a combination of numerical information obtained from measurements and

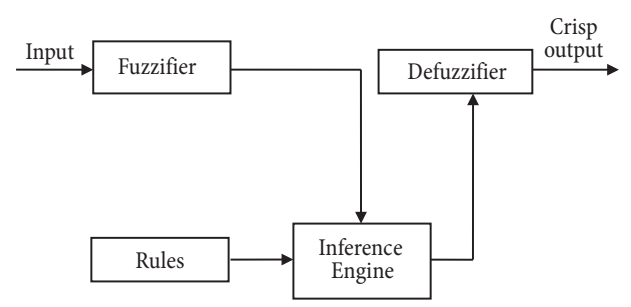

Fig. 3. Basic elements of a fuzzy logic linguistic information obtained from human experts is used to form the fuzzy rule base. In this case, rules are extracted from numerical data in the first step. In the next step this fuzzy rule base can (but need not) be supplemented with the rules collected from human experts. A fuzzy rule base obtained from numerical data can be used to solve the same type of problem solved by artificial neural networks. The inference engine of the fuzzy logic maps fuzzy sets onto fuzzy sets. A large number of different inferential procedures are found in the literature. In most papers and practical engineering applications, minimum inference or product inference is used.

During defuzzification, one value is chosen for the output variable. The literature also contains a large number of different defuzzification procedures. The final value chosen is most often either the value corresponding to the highest grade of membership or the coordinate of the center of gravity (Teodorovic, Vukadinovic 1998; Teodorović 1999).

\section{Previous Pavement Performance Models with The Fuzzy Logic Approach}

Generally, regression techniques have been used to obtain functions that are limited to the available database. The functions may suffer from inaccuracies due to error in data collection and recording (Shoukry et al. 1997). Therefore, there is a need to develop a more generalized pavement performance model to enable efficient management of large transportation networks. The fuzzy logic approach does not need any data to calibrate the model and therefore the model is universal.

Juang and Amirkhanian (1992) developed a fuzzy based Unified Pavement Distress Index (UPDI), considering the distresses of alligator cracking, rutting, potholes, patching, block cracks and longitudinal cracks that indicates pavement condition. In the developed model each distress has different weights for the calculating of UPDI. If UPDI $=0$ then the pavement is in perfect condition, if $U P D I=1$ then the pavement is in the worst condition.

Shoukry et al. (1997) developed a Fuzzy Distress Index (FDI) which combines the extent of structural distress with performance parameters such as roughness to describe the overall condition of a pavement section.

Bandara and Gunaratne (2001) used the mathematical techniques of fuzzy sets to deal with the subjectivity associated with the human judgment of distress severity and extent. Finally, a fuzzy pavement condition forecasting model was also developed by incorporating subjective probability assessments regarding pavement condition deterioration rates in the Markov transition process.

Previous fuzzy based pavement performance models mentioned above focused on few parameters, such as alligator cracking, rutting, potholes, patching, block cracks and longitudinal cracks (Juang, Amirkhanian 1992). However, Shoukry et al. (1997) proposed another fuzzy based model which has fourteen parameters, namely alligator cracking type, alligator cracking severity, alligator cracking extent, linear cracking type, 
linear cracking severity, linear cracking extent, sealing, average rut depth, patching, appearance, flushing/ravelling, shoulder condition, roughness and skid number. It is always possible to add another parameter into the model. Previous models were able to predict the current condition of pavement performance at project level. Therefore, there is a need for a new fuzzy logic model that could predict both the present and future performances of a pavement, which is the main aim of this present research.

\section{Developing a New Software for Pavement Performance}

A new fuzzy logic model has been developed to predict both the present and future performance of a pavement. The structure of the model for predicting pavement performance is shown in Fig. 4. The approach used in developing the model is fuzzy logic with two stages that are configured in such a way that it is different from previous fuzzy based models. The inputs to the first part of the model are variables that do not require any mechanistic measurements such as deflection. Output of the first part of the model is all possible distresses that probably occur, and these distresses are also the input for the second part of the model. The output of the second part of the model is the Fuzzy Pavement Serviceability Index (FPSI), that is, the pavement serviceability index based on the fuzzy logic approach. The reason for using the fuzzy logic approach with two stages is that there is no direct relationship between pavement serviceability index and factors causing distress. If only the second part of the model is used, the FPSI can be determined at project level. If the first and second parts of the model are used together, future FPSI can be predicted at network level. The model can also be used to conduct "what if" analyses to study the effects of various budget levels on future pavement condition.

Numerical variables in the model are considered with triangular membership functions and an example is shown in Fig. 5. However, linguistic variables were also used in the rule base. Table 2 shows variables used in the model and the ranges of variables. The effect of distresses on pavement is taken for each distress and rearranged to include other distresses. In the model, the distress having the highest membership degree was considered for each group (Table 3 ).

It is obvious that causes of distresses that are input in the first part of the model have no effect on any other distresses. Therefore, a sub-model was developed for each distress type to consider the effect of different factors. Some of the sub-models are shown in Fig. 6.

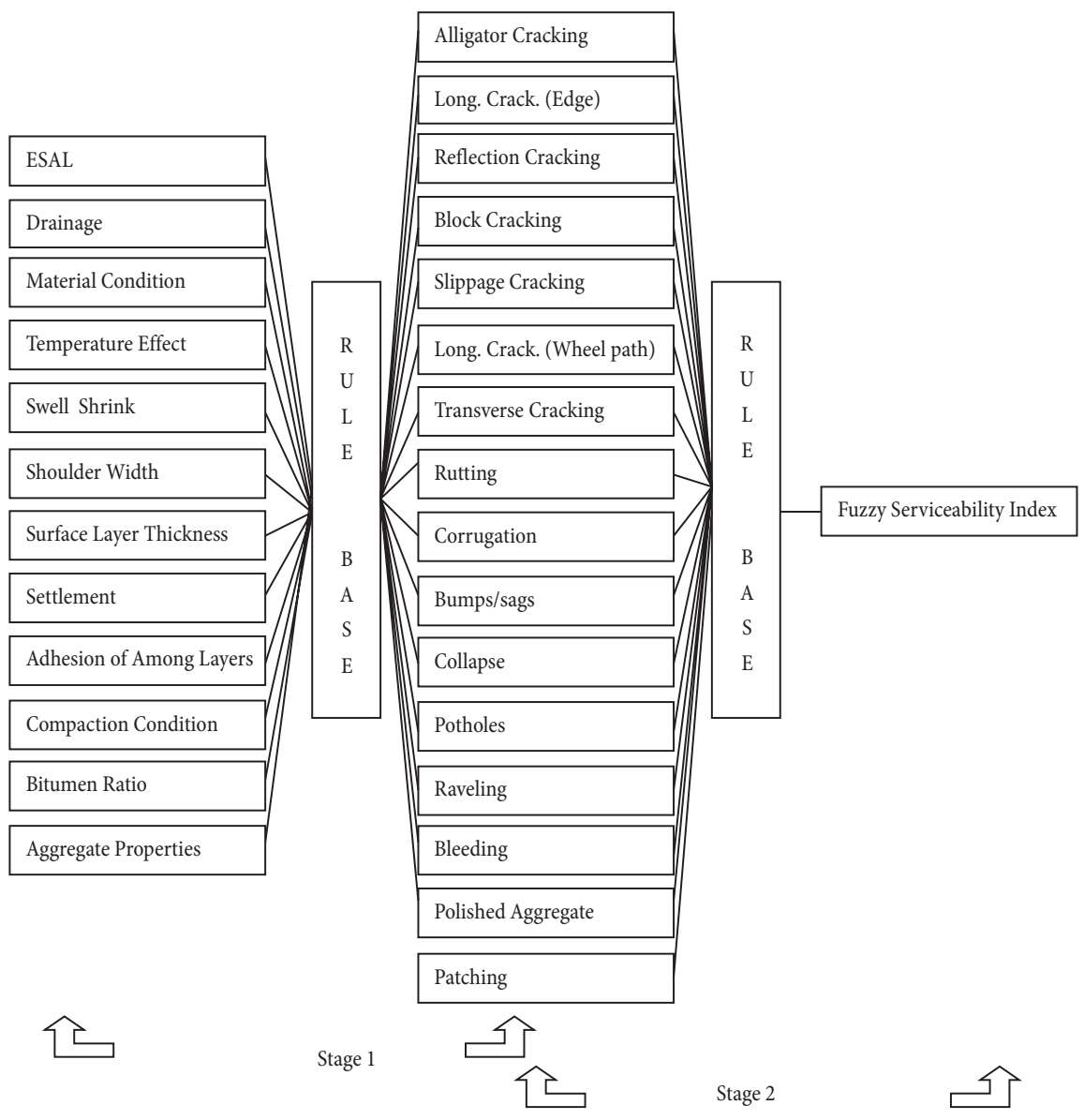

Fig. 4. General structure of the model 


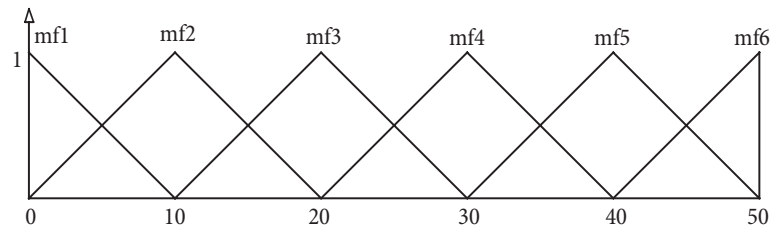

Fig. 5. Membership function of rutting

Table 2. Variables used in the model and ranges

\begin{tabular}{|c|c|c|}
\hline Linguistic Variables & \multicolumn{2}{|l|}{ Range } \\
\hline Drainage & \multicolumn{2}{|c|}{ Sufficient-Insufficient } \\
\hline Material condition & \multicolumn{2}{|c|}{ Bad-Average-Good } \\
\hline Swelling-shrinking & \multicolumn{2}{|c|}{ Little-Average-Much } \\
\hline Settlement & \multicolumn{2}{|c|}{ Little-Average-Much } \\
\hline Adhesion of among layers & \multicolumn{2}{|c|}{ Little-Average-Much } \\
\hline Compaction condition & \multicolumn{2}{|c|}{ Bad-Average-Good } \\
\hline Bitumen ratio & \multicolumn{2}{|c|}{ Little-Average-Much } \\
\hline Aggregate properties & \multicolumn{2}{|c|}{ Bad-Average-Good } \\
\hline Numerical Variables & Range $(\min \div \max )$ & Unit \\
\hline $\begin{array}{l}\text { Cumulative equivalent } \\
\text { axle load number }\end{array}$ & $0 \div 150000000$ & Number \\
\hline Climate & $0 \div 40$ & ${ }^{\circ} \mathrm{C}$ \\
\hline Shoulder with & $50 \div 300$ & $\mathrm{~cm}$ \\
\hline Surface layer thicknesses & $19 \div 27$ & $\mathrm{~cm}$ \\
\hline Alligator cracking & $0 \div 60$ & $\mathrm{~m}^{2}$ \\
\hline $\begin{array}{l}\text { Longitudinal cracking } \\
\text { (edge) }\end{array}$ & $0 \div 20$ & $\mathrm{~mm}$ \\
\hline Reflection cracking & $0 \div 20$ & $\mathrm{~mm}$ \\
\hline Block cracking & $0 \div 20$ & $\mathrm{~mm}$ \\
\hline Slippage cracking & $0 \div 20$ & $\mathrm{~mm}$ \\
\hline $\begin{array}{l}\text { Longitudinal cracking } \\
\text { (wheel path) }\end{array}$ & $0 \div 20$ & $\mathrm{~mm}$ \\
\hline Transverse cracking & $0 \div 20$ & $\mathrm{~mm}$ \\
\hline Rutting & $0 \div 50$ & $\mathrm{~mm}$ \\
\hline Corrugation & $0 \div 10$ & $\mathrm{~mm}$ \\
\hline Bumps/sags & $0 \div 20$ & $\mathrm{~mm}$ \\
\hline Collapse & $0 \div 50$ & $\mathrm{~mm}$ \\
\hline Potholes & $0 \div 50$ & $\mathrm{~mm}$ \\
\hline Raveling & $0 \div 10$ & $\mathrm{~m}^{2}$ \\
\hline Bleeding & $0 \div 100$ & $\mathrm{~m}^{2}$ \\
\hline Polished aggregate & $0 \div 100$ & $\mathrm{~m}^{2}$ \\
\hline Patching & $0 \div 100$ & $\mathrm{~m}^{2}$ \\
\hline Serviceability index & $1.25 \div 4.14$ & \\
\hline
\end{tabular}

All inputs and outputs are connected to each other with rules in the sub-models. Some rules related to Fig. $6 c$ are shown:

- if ESAL is much and compaction condition is bad and temperature is much then rutting is much;

- if ESAL is low and compaction condition is good and temperature is normal then rutting is little.
Table 3. Weights among different types of distresses for assessment of pavement conditions

\begin{tabular}{llc}
\hline \multirow{2}{*}{ Distress Type } & \multicolumn{2}{c}{ Weight } \\
\cline { 2 - 3 } & \multicolumn{1}{c}{ Description } & Letter Grade \\
\hline Alligator cracking & $\begin{array}{l}\text { Extremely } \\
\text { important }\end{array}$ & E \\
\hline $\begin{array}{l}\text { Rutting } \\
\begin{array}{l}\text { Potholes } \\
\text { Collapse }\end{array}\end{array}$ & $\begin{array}{l}\text { Very } \\
\text { important }\end{array}$ & D \\
\hline
\end{tabular}

Patching

Block cracking

Longitudinal cracking

Important

C

(wheel path)

Longitudinal cracking (edge)

Reflection cracking

Slippage cracking

Transverse cracking

Corrugation

\begin{tabular}{ll}
\hline Bleeding & Relatively \\
Raveling & unimportant \\
Polished aggregate & A \\
Bumps/sags & \\
\hline
\end{tabular}

a)

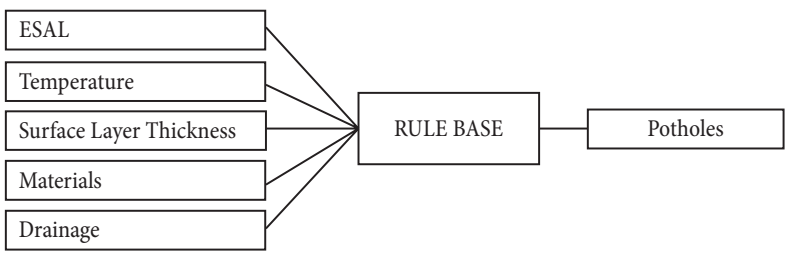

b)

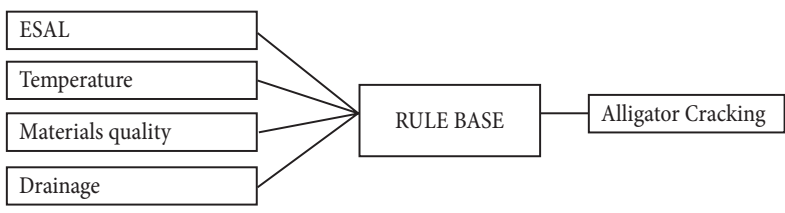

c)

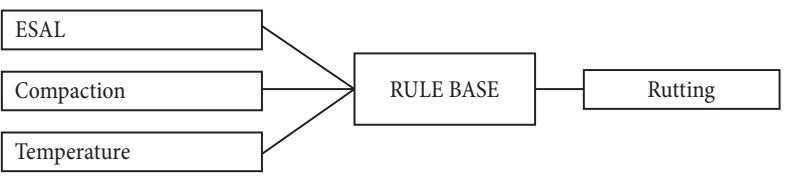

Fig. 6. Sub models of: a - potholes; b - alligator cracking; $c$ - rutting

To combine all sub-models, a computer program was developed in Visual Basic programming language. Fuzzy mathematics was used in calculations. The algorithm used in the program is shown in Fig. 7 and an output of the program is shown in Fig. 8. The user can select either project level or network level pavement performance prediction. If the project level is chosen, distress type and its extent needs to be entered. However, if network level, in other words future pavement performance prediction is chosen, factors causing distresses need to be known. 


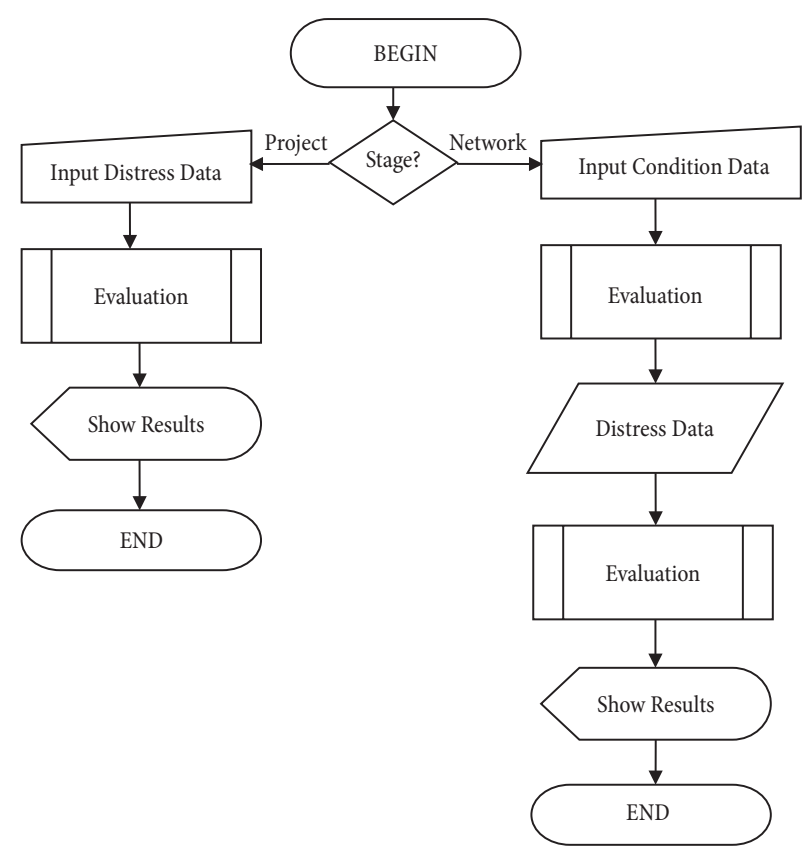

Fig. 7. Algorithm used in the program

\section{Case Study}

To show pavement performance change with different variables, user friendly software was developed in Visual Basic programming language. A change in serviceability index could be obtained for each variable causing distresses and ESAL. It is possible to obtain many graphics to show the effect of all variables, and some of them are shown here. Fig. 9 shows the effect of drainage on the FPSI. As the number of ESAL was increased, the FPSI considerably decreased, and distresses such as alligator cracking, edge cracking and settlement may occur. Fig. 10 shows the effect of pavement thickness on the FPSI. As the pavement thickness increased, the FPSI increased. The effect of material quality used in pavement structure on the FPSI is shown in Fig. 11.

As expected, low quality material gives a lower FPSI and at high ESAL values, the FPSI decreases considerably. Fig. 12 shows the effect of compaction of pavement materials. Low compaction causes a dramatic decrease in the FPSI from the beginning and shows how compaction is important for the FPSI. Because of this difference, the FPSI results were multiplied by 20 .

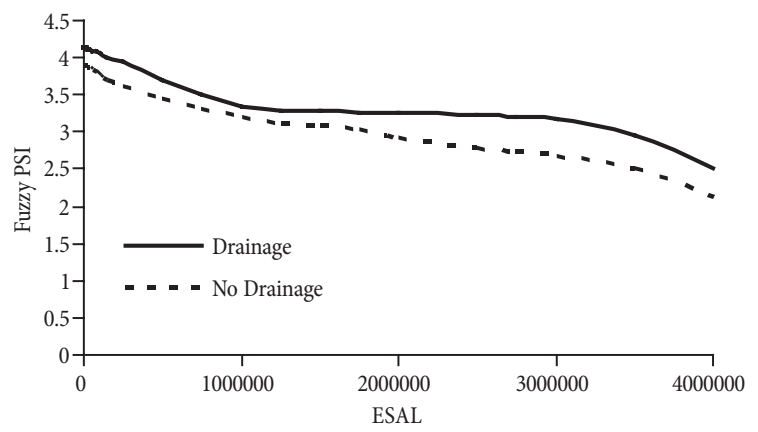

Fig. 9. Relationship of ESAL with FPSI of drainage

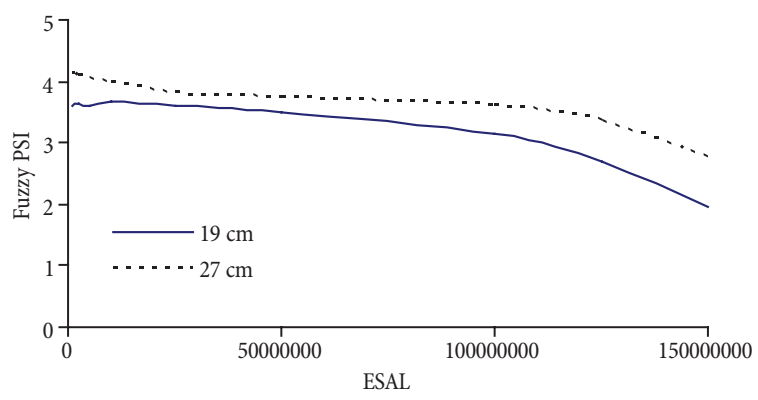

Fig. 10. Relationship of ESAL with FPSI of various layer thicknesses values

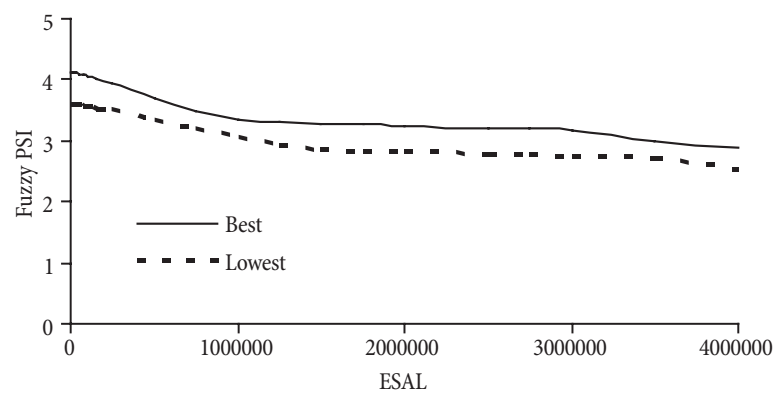

Fig. 11. Relationship of ESAL with FPSI of various materials quality

Fig. 13 shows effect of adhesion of between layers. As it can be seen in this figure, adhesion is one of the important factors for pavement performance. The adhesion inadequate is decrease of the pavement performance with ESAL value.

Another important factor is compaction of the pavement layers. Effect of compaction was given in

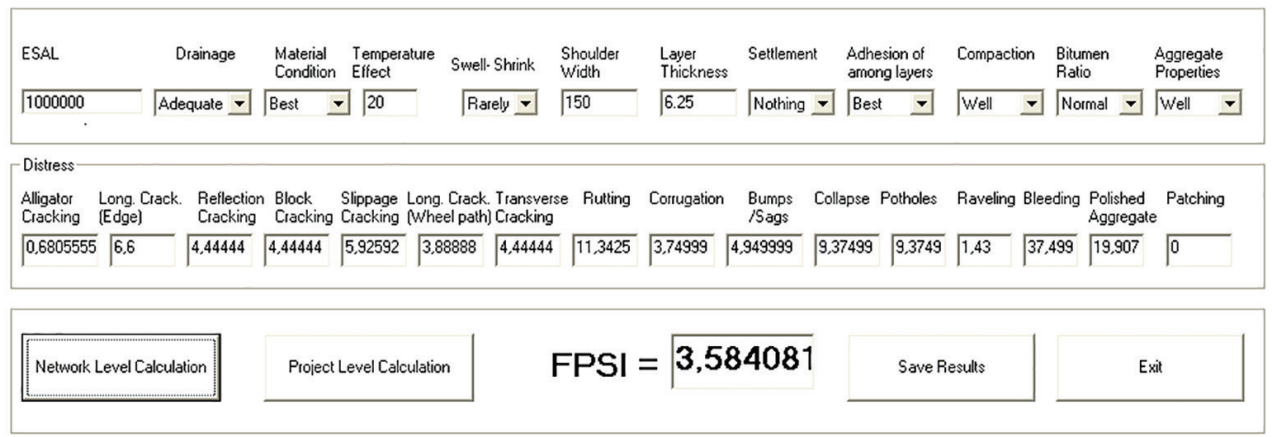

Fig. 8. Result of the calculation of FPSI value 
Fig. 14. The compaction inadequate is dramatically decreased of the pavement performance more than adhesion inadequate. Weather conditions are one of the important factors for pavement performance because of the characteristics of bitumen change depending on the temperature.

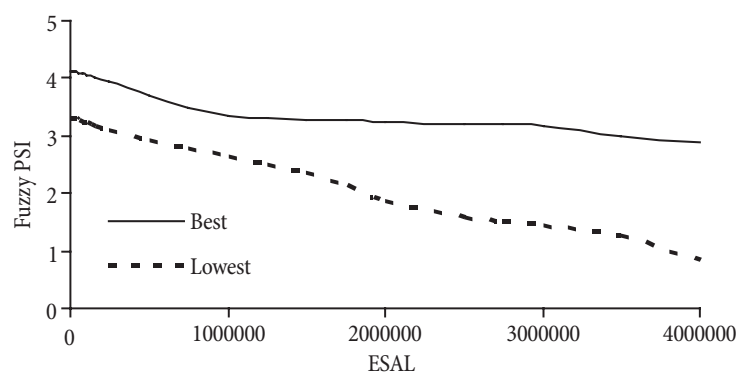

Fig. 12. Effect of compaction of pavement materials

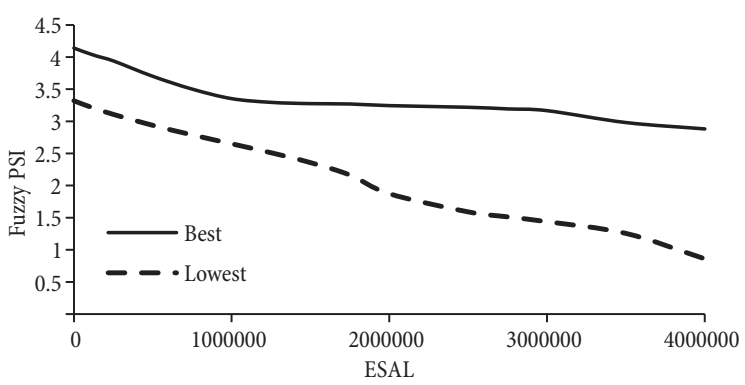

Fig. 13. Effect of adhesion of between layers
Fig. 15 shows that effect of temperature. As it can be seen in this figure, more high and low temperature is negative effect of the pavement performance. Also this negative effect is increase with traffic value.

To demonstrate model validation, data (Table 4) from Jahren et al. (1998) were compared to the model

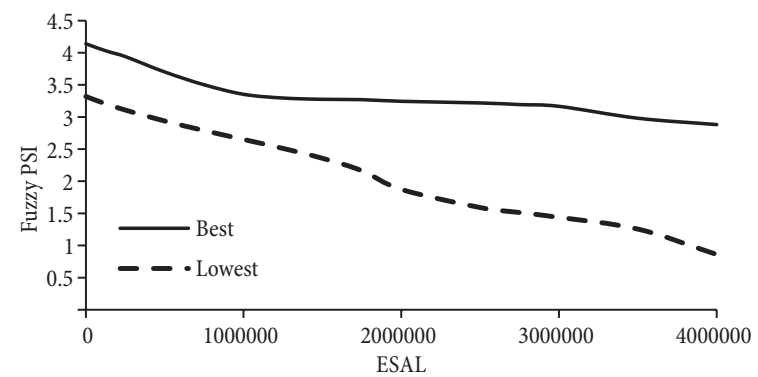

Fig. 14. Effect of Compaction

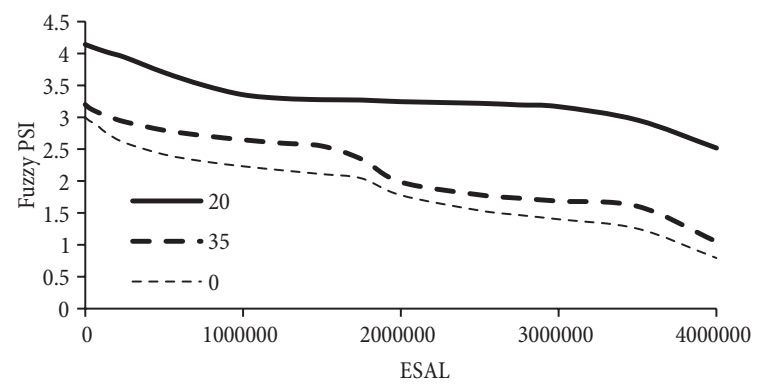

Fig. 15. Effect of Temperature

Table 4. Road surveyed 1996 and 1997 (Jahren et al. 1998)

\begin{tabular}{|c|c|c|c|c|c|c|c|c|c|c|c|c|c|c|c|}
\hline $\begin{array}{l}\hat{\Xi} \\
\Xi \\
0 \\
0\end{array}$ & 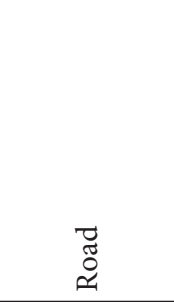 & 它 & $\underset{\pi}{\infty}$ & 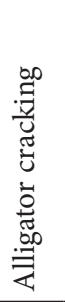 & 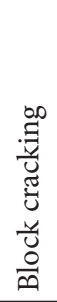 & 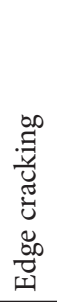 & 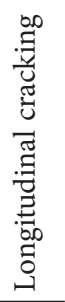 & $\begin{array}{l}\stackrel{\infty}{\Xi} \\
\stackrel{\Xi}{0} \\
\simeq\end{array}$ & $\stackrel{\infty}{\stackrel{\Xi}{\Xi}}$ & 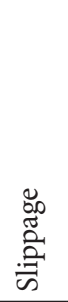 & 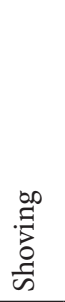 & 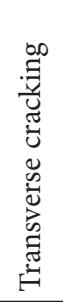 & $\ddot{n}$ & $\vec{\circlearrowright}$ & 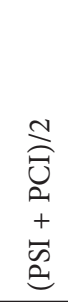 \\
\hline Guthrie & IA-4 & 820 & 2 & 0 & 0 & 0 & 0 & 0 & 0 & 0 & 0 & 0 & 90 & 100 & 95.0 \\
\hline Butler & $\mathrm{T}-16$ & 470 & 3 & 0 & 0 & 0 & 0 & 0 & 0 & 0 & 0 & 0 & 81 & 100 & 90.7 \\
\hline Calhoun & IA-175 & 1920 & 3 & 0 & 0 & 0 & 0 & 0 & 0 & 0 & 0 & 0 & 81 & 100 & 90.7 \\
\hline Muscatine & $\mathrm{F}-70$ & 950 & 3 & 0 & 0 & 0 & 0 & 0 & 0 & 0 & 0 & 0 & 82 & 100 & 90.8 \\
\hline Hardin & D-35 & 665 & 4 & 0 & 8 & 0 & 0 & 0 & 3 & 0 & 0 & 8 & 65 & 85 & 75.0 \\
\hline Boone & E-52 & 290 & 5 & 0 & 0 & 3 & 0 & 0 & 0 & 0 & 0 & 2 & 73 & 95 & 83.8 \\
\hline Muscatine & G-28 & 940 & 5 & 0 & 0 & 0 & 0 & 0 & 0 & 0 & 0 & 2 & 73 & 98 & 85.3 \\
\hline Tama & $\mathrm{V}-18$ & 550 & 5 & 0 & 0 & 0 & 0 & 0 & 0 & 0 & 0 & 0 & 70 & 100 & 85.0 \\
\hline Cerro & Gordo S.S & 600 & 6 & 0 & 0 & 0 & 4 & 0 & 1 & 0 & 0 & 14 & 61 & 81 & 71.2 \\
\hline Tama & E-66 & 1080 & 6 & 0 & 0 & 0 & 0 & 0 & 0 & 0 & 0 & 6 & 61 & 94 & 77.0 \\
\hline Winnebago & $\mathrm{R}-34$ & 620 & 6 & 0 & 0 & 0 & 0 & 0 & 0 & 0 & 0 & 10 & 63 & 90 & 76.3 \\
\hline Winnebago & $\mathrm{R}-60$ & 340 & 6 & 0 & 28 & 0 & 0 & 0 & 0 & 0 & 0 & 0 & 63 & 72 & 67.3 \\
\hline Cerro & Gordo B-43 & 570 & 7 & 0 & 12 & 0 & 11 & 0 & 8 & 0 & 14 & 3 & 68 & 77 & 72.3 \\
\hline Clinton & $\mathrm{Z}-30$ & 850 & 7 & 0 & 0 & 0 & 0 & 0 & 0 & 6 & 0 & 1 & 64 & 93 & 78.4 \\
\hline Greene & IA-144 & 1110 & 7 & 33 & 1 & 0 & 4 & 0 & 17 & 0 & 0 & 7 & 58 & 60 & 59.0 \\
\hline Boone & $198 \mathrm{TH}$ & 300 & 8 & 18 & 0 & 0 & 3 & 0 & 17 & 0 & 0 & 0 & 59 & 71 & 64.9 \\
\hline Muscatine & Y-14 & 990 & 9 & 0 & 0 & 0 & 5 & 16 & 9 & 54 & 0 & 7 & 61 & 52 & 56.4 \\
\hline Clinton & E-50 & 520 & 10 & 0 & 0 & 0 & 1 & 0 & 10 & 0 & 0 & 15 & 51 & 81 & 66.2 \\
\hline
\end{tabular}


results (Fig. 16). To this aim, the FPSI was estimated only for use at network level (second level). As seen in Table 2, the serviceability index (FPSI) was estimated using $0 \div 5$ ranges. However, Jahren et al. (1998) estimated the PCI (pavement condition index) using $0 \div 100$ ranges. As a result of this difference, the FPSI results were multiplied by 20 . The comparison thus resulted in a regression value of 0.80. Actually, if Jahren et al. (1998) were to not use cold in-place asphalt recycling in their work, it could be of more value. Also, they obtained to regression value as 0.78 for PSI and 0.49 PCI using linear regression lines extrapolating into the future and 95\% confidence intervals. Our model has more high regression value than that work. Some statistical compares are given in Table 5. As seen in the Table, our model has more successful values than the PCI calculations.

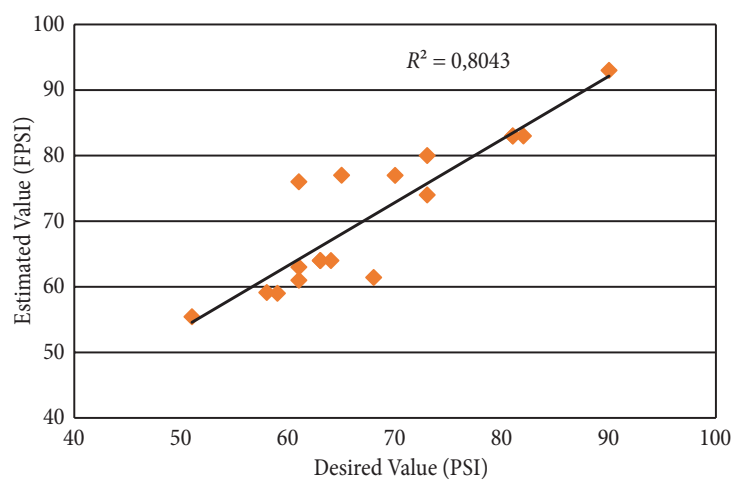

Fig. 16. Comparison of desired value with estimated value

Table 5. Comparing of models statistical values

\begin{tabular}{lccc}
\hline & PSI & PCI & FPSI \\
\hline Mean (average) & 68 & 86.05556 & 70.94267 \\
\hline Standard deviation & 10.1865 & 14.79059 & 10.93558 \\
\hline $\begin{array}{l}\text { Variance } \\
\text { (standard deviation) }\end{array}$ & 103.76471 & 218.76144 & 119.587 \\
\hline $\begin{array}{l}\text { Population standard } \\
\text { deviation }\end{array}$ & 9.89949 & 14.37387 & 10.62748 \\
\hline $\begin{array}{l}\text { Variance (population } \\
\text { standard deviation) }\end{array}$ & 98 & 206.60802 & 112.94328 \\
\hline $\begin{array}{l}\text { Sum of Squared } \\
\text { Error (SSE) }\end{array}$ & 1764 & 3718.9445 & 2032.979 \\
\hline $\begin{array}{l}\text { Mean Squared } \\
\text { Error (MSE) }\end{array}$ & 98 & 206.60803 & 112.94328 \\
\hline
\end{tabular}

\section{Conclusions}

A new model for performance prediction of flexible pavements was developed using the fuzzy logic approach. The model is different from previous fuzzy based performance models since it has two stages to predict both the current and future performance of asphalt pavements. The addition of a new parameter or excluding a parameter is always possible, therefore the model is more flexible than previous flexible pavement performance models based on a specific dataset. Another advantage of the model is it finds answers to 'what- if' scenarios. The model developed in the research work considers all distresses in the pavement and causes of these distresses. Therefore, the model allows predicting the present condition of the pavement at project level, and in addition, the future condition of the pavement can also be predicted at network level.

Considering all the work, this model is more suitable for network level. The model can also predict the performance of new and rehabilitated pavements.

The new methodology proposed in the paper can be used in developing countries and small municipalities where only limited resources and datasets are available. A possible limitation of the model may be that collecting the required date using the model as input may be more costly and time consuming. The use of automatic equipment is more useful in some conditions for collecting pavement performance data.

The fuzzy logic model with two layers can be easily used when there is no relationship between inputs and outputs.

Nowadays, there is a lot of automatic equipment for pavement performance measurement. But they are so expensive and complicate. Excellent condition is use of all mechanistic equipment and all parameters effecting to pavement performance if it possible.

\section{References}

AASHO. 1962. The AASHO Road Test Report 5: Pavement Research. Highway Research Board, American Association of State Highway Officials (AASHO), National Academy of Sciences - National Research Council, Washington, USA. $352 \mathrm{p}$.

AASHTO. 1986. AASHTO Guide for Design of Pavement Structures: Volume 2. American Association of State Highway and Transportation Officials (AASHTO), 3rd edition, Washington, USA. 248 p.

AASHTO. 1993. AASHTO Guide for Design of Pavement Structures. American Association of State Highway and Transportation Officials (AASHTO), 4th edition, Washington, USA. 624 p.

Akhter, G. F.; Witczak, M. W. 1985. Sensitivity of flexible pavement performance to bituminous mix properties, Transportation Research Record 1034: 70-79.

Attoh-Okine, N. O. 2001. Grouping pavement condition variables for performance modeling using self-organizing maps, Computer-Aided Civil and Infrastructure Engineering 16(2): 112-125. http://dx.doi.org/10.1111/0885-9507.00218

Attoh-Okine, N. O. 1999. Analysis of learning rate and momentum term in backpropagation neural network algorithm trained to predict pavement performance, Advances in Engineering Software 30(4): 291-302. http://dx.doi.org/10.1016/S0965-9978(98)00071-4

Bandara, N.; Gunaratne, M. 2001. Current and future pavement maintenance prioritization based on rapid visual condition evaluation, Journal of Transportation Engineering 127(2): 116-123.

http://dx.doi.org/10.1061/(ASCE)0733-947X(2001)127:2(116)

Berger, L.; Greenstein, J.; Hoffman, M.; Uzan, J. 1991. Practical applications of models for pavement maintenance management, Journal of Transportation Engineering 117(4): 382-397.

http://dx.doi.org/10.1061/(ASCE)0733-947X(1991)117:4(382) 
Bianchini, A.; Bandini, P. 2010. Prediction of pavement performance through neuro-fuzzy reasoning, Computer-Aided Civil and Infrastructure Engineering 25(1): 39-54. http://dx.doi.org/10.1111/j.1467-8667.2009.00615.x

Butt, A. A.; Shahin, M. Y.; Carpenter, S. H.; Carnahan, J. V. 1995. Application of Markov process to pavement management systems at network level, in Conference Proceedings: Third International Conference on Managing Pavements, 22-26 May 1994, San Antonio, Texas. Volume 2, 159-172. Available from Internet: http://pavementmanagement.org/ ICMPfiles/1994038.pdf

Cedergren, H. R. 1974. Drainage of Highway and Airfield Pavements. Wiley. $285 \mathrm{p}$.

Cheng, H. D.; Chen, J.-R.; Glazier, C.; Hu, Y. G. 1999. Novel approach to pavement cracking detection based on fuzzy set theory, Journal of Computing in Civil Engineering 13(4): 270-280.

http://dx.doi.org/10.1061/(ASCE)0887-3801(1999)13:4(270)

Choi, J.-H.; Adams, T. M.; Bahia, H. U. 2004. Pavement roughness modeling using back-propagation neural networks, Computer-Aided Civil and Infrastructure Engineering 19(4): 295-303.

http://dx.doi.org/10.1111/j.1467-8667.2004.00356.x

Fwa, T. F.; Sinha, K. C. 1986. Routine maintenance and pavement performance, Journal of Transportation Engineering 112(4): 329-344.

http://dx.doi.org/10.1061/(ASCE)0733-947X(1986)112:4(329)

Fwa, T. F.; Sinha, K. C. 1991. Pavement performance and lifecycle cost analysis, Journal of Transportation Engineering 117(1): 33-46. http://dx.doi.org/10.1061/(ASCE)0733947X(1991)117:1(33)

Fwa, T. F.; Sinha, K. C. 1992. Quantification of agency and user values of pavement performance, Journal of Transportation Engineering 118(1): 84-98.

http://dx.doi.org/10.1061/(ASCE)0733-947X(1992)118:1(84)

Haas, R. C. G.; Hudson, W. R.; Zaniewski, J. P. 1994. Modern Pavement Management. Krieger Pub Co. 604 p.

Jahren, C. T.; Cawley, B.; Ellsworth, B.; Bergeson, K. L. 1998. Review of cold in-place asphalt recycling in Iowa, in Crossroads 2000: Proceedings, 19-20 August 1998, Ames, Iowa, 259-263.

Juang, C. H.; Amirkhanian, S. N. 1992. Unified pavement distress index for managing flexible pavements, Journal of Transportation Engineering 118(5): 686-699.

http://dx.doi.org/10.1061/(ASCE)0733-947X(1992)118:5(686)

Jung, F. W.; Kher, R. K.; Phang, W. A. 1976. Subsystem for predicting flexible pavement performance, Transportation Research Record 572: 15-28.

Kargah-Ostadi, N.; Stoffels, S. M.; Tabatabaee, N. 2010. Network-level pavement roughness prediction model for rehabilitation recommendations, Transportation Research Record 2155: 124-133. http://dx.doi.org/10.3141/2155-14

Lytton, R. L. 1987. Concepts of pavement performance prediction and modeling, in Proceedings of the Second North American Pavement Management Conference, 2-6 November 1987, Toronto, Ontario, Canada, 2.4-2.19. Available from Internet: http://www.pavementmanagement.org/ICMPfiles/1987033.pdf

Madanat, S.; Prozzi, J. A.; Han, M. 2002. Effect of performance model accuracy on optimal pavement design, ComputerAided Civil and Infrastructure Engineering 17(1): 22-30. http://dx.doi.org/10.1111/1467-8667.00249
Moazami, D.; Behbahani, H.; Muniandy, R. 2011. Pavement rehabilitation and maintenance prioritization of urban roads using fuzzy logic, Expert Systems with Applications 38(10): 12869-12879. http://dx.doi.org/10.1016/j.eswa.2011.04.079

Nakamura, V. F. 1962. Serviceability Ratings of Highway Pavements. Publication FHWA/IN/JHRP-62/06. Joint Highway Research Project, Indiana Department of Transportation and Purdue University, West Lafayette, Indiana. http://dx.doi.org/10.5703/1288284313603

Owusu-Ababio, S. 1998. Effect of neural network topology on flexible pavement cracking prediction, Computer Aided Civil and Infrastructure Engineering 13(5): 349-355. http://dx.doi.org/10.1111/0885-9507.00113

Pan, N.-F.; Ko, C.-H.; Yang, M.-D.; Hsu, K.-C. 2011. Pavement performance prediction through fuzzy regression, Expert Systems with Applications 38(8): 10010-10017. http://dx.doi.org/10.1016/j.eswa.2011.02.007

Prozzi, J. A.; Madanat, S. M. 2003. Incremental nonlinear model for predicting pavement serviceability, Journal of Transportation Engineering 129(6): 635-641.

http://dx.doi.org/10.1061/(ASCE)0733-947X(2003)129:6(635)

Saraf, C. L. 1998. Pavement Condition Rating System: Review of PCR Methodology. Report No FHWA/OH-99/004. 126 p.

Shahin, M. Y. 2006. Pavement Management for Airports, Roads, and Parking Lots. 2nd edition. Springer. 572 p.

Shahin, M. Y.; Becker, J. M. 1984. Development of performance prediction models for airfield pavements, Transportation Research Record 985: 25-33.

Shoukry, S. N.; Martinelli, D. R.; Reigle, J. A. 1997. Universal pavement distress evaluator based on fuzzy sets, Transportation Research Record 1592: 180-186. http://dx.doi.org/10.3141/1592-20

Tavakoli, A.; Lapin, M. S.; Figueroa, J. L. 1992. PMSC: pavement management system for small communities, Journal of Transportation Engineering 118(2): 270-281.

http://dx.doi.org/10.1061/(ASCE)0733-947X(1992)118:2(270)

Teodorović, D. 1999. Fuzzy logic systems for transportation engineering: the state of the art, Transportation Research Part A: Policy and Practice 33(5): 337-364. http://dx.doi.org/10.1016/S0965-8564(98)00024-X

Teodorovic, D.; Vukadinovic, K. 1998. Traffic Control and Transport Planning: A Fuzzy Sets and Neural Networks Approach. Springer. $387 \mathrm{p}$.

Terzi, S. 2007. Modeling the pavement serviceability ratio of flexible highway pavements by artificial neural networks, Construction and Building Materials 21(3): 590-593. http://dx.doi.org/10.1016/j.conbuildmat.2005.11.001 